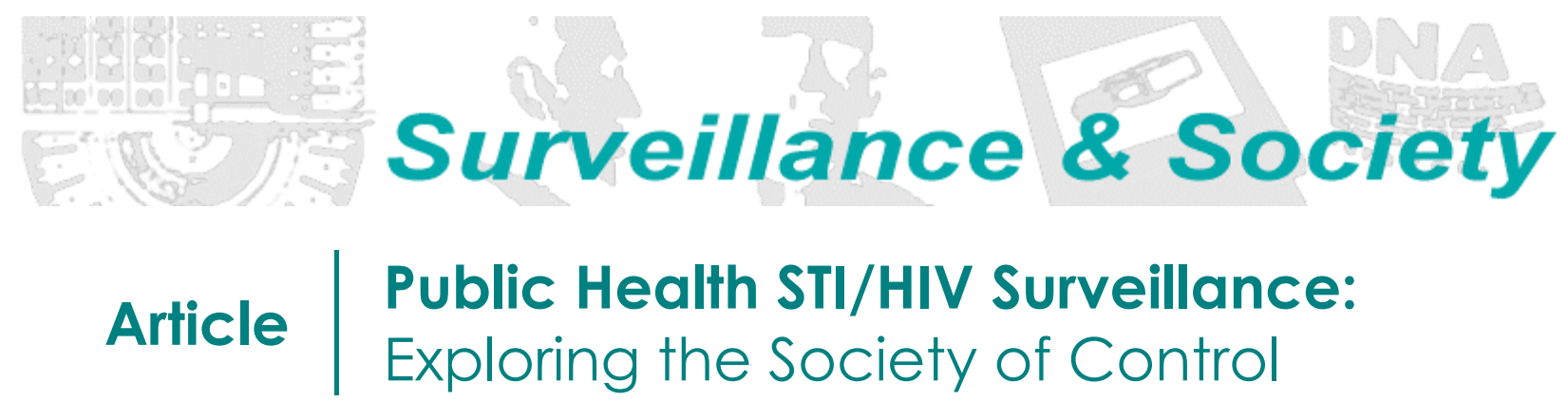

\title{
Patrick O'Byrne
}

School of Nursing, University of Ottawa. pjobyrne@uottawa.ca

\section{Dave Holmes}

School of Nursing, University of Ottawa.

\begin{abstract}
While Michel Foucault asserted that the sovereign style of rule had disappeared, instead replaced by a disciplinary society (wherein individuals were trained/domesticated in a variety of social institutions), years later, Gilles Deleuze recounted how this social structure had again changed. Within this new system, which Deleuze labelled the society of control, social networks have become so densely intertwined that it no longer matters whether or not someone is disciplined in accordance with social rules because now they are entrapped within a web that would more often than not ensure that socially appropriate trajectories are maintained. Using Deleuze's framework about the society of control, in this paper, we explore the current public health STI/HIV surveillance system. The outcome of this exploration is the suggestion that the system is, in fact, an example of a densely intertwined (rhizomatic) control society, and that it is maintained through the desires of the people.
\end{abstract}

\section{Introduction}

In the mid to late 20th century, two influential French philosophers each described what they believed was the structure of European society. The first of these was Michel Foucault, who, in 1977, observed that a disciplinary society had replaced the rule of sovereigns - a process that involved the replacement of the single authoritarian ruler with a series of distinct institutions (such as, the family, the school, the factory, and the army, amongst others). These institutions, Foucault argued, all worked independently, but in conjunction, to enforce power onto individuals.

Two decades later, a second philosopher, Gilles Deleuze $(1992 ; 1998)$ argued that the prevailing Western social structure had again transformed. This time, however, society had reorganized into what Deleuze called a "society of control". Indeed, in his Postscript on Societies of Control, Deleuze (1992) delineated the processes by which the Foucauldian disciplinary social structure (wherein individuals are disciplined within specific institutions to match pre-established social norms) had slowly transformed into our present social state - a social system in which behaviour control neither focuses strictly on the individual, nor occurs exclusively within specific institutions. Instead, social control is now achieved in a fluid and unnoticeable manner because the instruments of control have begun to operate beyond their original containments, beyond the family, the school, the factory, that is.

In making the postulation that the modern social system is a society of control, Deleuze (1992) did not suggest that the techniques of the disciplinary society had disappeared. Rather, he stated that disciplinary mechanisms still function; they just do so differently now (Deleuze, 1998). This means that while the 
disciplinary-society regulatory mechanisms continue to operate, they now do so in many new ways/places. The outcome, from Deleuze's perspective, is that the contemporary society of control is so diffuse, so constant, and so subtle that we (as the individuals being 'controlled') often neither recognize the techniques nor are even aware of their effects (Deleuze, 1992).

In this paper, we will support Deleuze's argument that the contemporary social system is a society of control by analyzing current public health surveillance practices. To accomplish this we will, first, outline the disciplinary society that Foucault (1977) described, second, detail Deleuze's $(1992 ; 1998)$ ideation of the society of control and how it arose from the disciplinary society, third, provide an overview of the sequence of events that occurs in Ontario (a Canadian province) when an individual tests positive for a reportable sexually transmitted infection (STI) or HIV, and fourth, discuss how Ontario's STI/HIV reporting system supports the idea that contemporary society is one of control. To further develop the final discussion, we will add two other Deleuzo-Guattarian $(1983$; 1987) concepts: the rhizome, which will be used to illuminate the network structure of the society of control; and striation, which will be used to further explain the rhizome.

\section{Sovereignty, Discipline, and Control: The Transition}

\section{From Sovereignty to Disciplinary Society}

In his book, Discipline and Punish, Michel Foucault (1977) argued that European sovereigns had lost their dominance, and the result was that their (symbolic) power had mutated into a series of disciplinary technologies permeating various settings. In other words, a system in which order was enforced through a variety of social structures, such as, the school, the barracks, the factory, and the hospital, had replaced the individual who had ruled by "divine right" (i.e., the divine right of kings). In taking note of how these institutions function, Foucault (1977) suggested that the goal of regulatory organizations was to observe, examine, and rank the unique attributes of each individual so as to normalize (i.e., discipline) any real or potential abnormalities. That is, individuals were thoroughly scrutinized in order to discipline them into pre-specified outcomes that coincided with their socio-economic and cultural status $(1978 ; 1985 ; 1986)$.

To describe this process at its most global level, Foucault (1978) coined the term bio-power - a concept, which he used to describe an array of mechanisms that focus on the body, as machine, in order to render it docile, conformed, and useful. Ultimately, this means that bio-power should be understood as a productive form of power that is able to "optimize, administer, and multiply life, [by] subjecting it to precise controls and comprehensive regulation" (Rainbow, 1984, 259). Foucault (1978) argued that, while violence could serve as a means for accomplishing this task, a defining feature of the disciplinary society was that such overt correction was used much less frequently. He suggested, instead, that the correction of deviance had become focused on "generating forces, making them [i.e., individuals] grow [by] ordering them, rather than ... [by] impeding them, making them submit, or destroying them" (Rainbow, 1984, 259). Thus, the new political rationality was to "incite, reinforce, control, monitor, optimize, and organize" through a nonviolent affiliation of bodies with the capability of rendering each more productive (Rainbow, 1984, 259).

According to Foucault (1977), the disciplinary society can be envisaged as a series of institutions through which individuals, first, pass, and second, acquire the regulatory practices that they must internalize and impose on themselves well beyond the physical boundaries wherein they were learned. This process, which Foucault called the ethics of the self, occurred in milieux such as the family, the school, and the factory. For example, the school produced students who knew how to sit, listen, and think; meanwhile, the factory created the worker who could produce, endure, and operate. In a step-wise fashion from family to school to factory, these institutions promoted the act of learning how to police oneself (i.e., the ethics of self). The outcome was an assessment of individuality for the sole purpose of determining (through observation, examination, and normalization) if an individual possessed any characteristics which needed modification. Were there any attributes, in other words, which failed to correspond with the socially-predesignated mould. In its totality, this process served to ensure that everyone had adequately learned to maintain his/her behaviour appropriately. 
The underlying goal of these institutions was to achieve in-depth, long-range, and far-reaching effects to the point where individuals would continue to behave as prescribed after they had left their formative institutions (Foucault, 1977). In this way, the disciplinary society exhibited a decreased emphasis on overt, externally imposed, and violent order, and a corresponding increase in the degree of self-control that was demanded from each person. For Foucault $(1977$; 1986; 1997), this meant that a series of investments in, and into, the body left each person capable, willing, and more importantly, desiring to police and control his/her own thoughts, emotions, and actions.

\section{From Discipline to a Society of Control}

Nearly two decades after Foucault described the above disciplinary system, Gilles Deleuze (1992) argued in Postscript on Societies of Control that the disciplinary form of society had reached its pinnacle at the beginning of the twentieth century; and that since that time, the social system had transformed. It had become a society of control. Of significant importance is that Deleuze $(1992 ; 1998)$ identified this development as a transformation, not a replacement. He maintained that the society of control had not displaced the disciplinary society, but rather, that this new social structure had evolved from the disciplinary society which had preceded it. This is the argument that the modern social system is not simply an enhanced disciplinary society, but that it is a distinctly new form of social organization and control.

This argument is based on Deleuze's observations that contemporary society acquired even more subtle methods of governing individuals who are resistant to external and internal command. It did so, Deleuze (1992) argued, by surpassing the individual as the base unit of social control. Within a control society, smaller and smaller analyses occur: the organ, the tissue, the cell, the molecule, and so forth. The individual has become less important. As such, the regulatory functions associated with disciplinary structures are now imposed regardless of whether or not individuals have been captured within the institutional structures that are essential components of disciplinary societies. Thus, one no longer needs to be within a given disciplinary structure to experience its effects.

This signifies that individuals no longer transition from one space to another. It is not that individuals do not enter these disciplinary institutions; rather, it is that one never fully leaves them. The specific locus of order which exists during a disciplinary society disappeared because control is now everywhere and nowhere at the same time. For example, education is no longer restricted to a specific time in an individual's life, nor to conventional school environments - distance education programs popular television channels show documentaries, "learning series", and the enormous influence of "talk shows" with vast daily audiences. Furthermore, while according to Foucault (1977), the individual moved from the domain of the school to the factory, Deleuze (1992) described a more recent system within which individuals begin working while still in school, and then continue their schooling while at work. The subtle, but profound, differences between the former and the latter lies in, first, the amount of time spent on each of the activities, and second, the goals which individuals ascribe to each. Does the person work to support school, or go to school to enhance their work? Thus, the current social system no longer corresponds with what Foucault described in 1977 as being a disciplinary society. In contrast, the contemporary social network has become so interrelated that it is exceedingly difficult to be exclusively within the grasp of only one institution.

Indeed, within this new system of governance, society has become so densely interconnected that individuals are increasingly controlled, regardless of whether or not they are (a) within the physical confines of these apparatuses, and (b) properly disciplined in accordance with the moulds of these apparatuses. Thus, the limited number of normative behavioural moulds that existed during the disciplinary society have changed into modulations. Money, as a prime example of the society of control, is no longer based on the stable measure of gold; it is now based on comparisons between various perpetually-changing currency values. The outcome is that the society of control is now an "ultra-rapid and free-floating" system of modulation (1992, 3-4). In the social sphere. this means that whether or not 
internalization of the behaviours expected by within the disciplinary society is achieved is less of a concern because in the society of control a myriad of mechanisms are invoked to ensure that everyone maintains a somewhat socially acceptable trajectory.

An emphasis on trajectory indicates that it is not this or that type of person that is the goal within the society of control. Of importance are the flows and fluctuations of each body. To explain further: within the disciplinary society that Foucault described, individuals were forced to become specific ideas: this or that type of man/woman, this or that type of child/youth, and so forth. The soldier, who is one of Foucault's classic examples, is the type of person that a recruit is to be made into. In such a case, all other expressions of self were deviations. Individuality was thus the existence of peculiarities that had not been adequately effaced by the disciplinary institutions. Deleuze's society of control, by comparison, permits a nearly endless expression of individuality: the macho-man, the gay man, the metro-sexual, et cetera, the lip-stick lesbian, the bull-dyke, the blue-jean femme, et cetera. As part of this, however, each individual must render him/herself open and exposed at all times. Be gay, for example, but do so while ensuring that your sexuality is fully exposed to sexually transmitted infection (STI) and HIV management workers. In the new social system, one's every movement must be known, tracked, and analyzed.

One such analysis occurs by credit card companies, who evaluate whether purchases made on credit are likely to have been made, or at least authorised, by the credit card holder. If the credit card company suspects that a transaction is fraudulent, they immediately cancel the credit card and notify the owner. This process of perpetual tracking and analysis, however, occurs unknown to the individual who legitimately possess the credit card. Most readily, this is because credit card owners are given a 'green light' to purchase because the transactions being placed on the card resemble their usual patterns of consumption.

The process by which credit card companies allow or deny purchases exemplifies the society of control. Now, one does not navigate institutions with a physical key that fits only one specific lock; instead, one uses what Deleuze described as a password - an amorphous mechanism of tracking which permits, to a large extent, free movement. Such uninhibited movement, however, is precarious. In relation to the foregoing credit card example, one can always have a transaction denied, and then be forced to produce an alternative form of payment. The password is able to garner, or restrict, such freedom because an array of ubiquitous and unseen mechanisms continuously monitors the user's activity. As Deleuze (1992) states, "what counts is not the barrier, but the computer that tracks each person's position - licit or illicit - and effects a universal modulation" (p.7). The goal in the society of control is thus not to rely on individuals policing their own behaviour, but rather, to have them submit to continuous surveillance; but to do so while continuing to believe that they have unlimited freedom.

Societies of control offer such an illusion of freedom because they make many options available to individuals (Zizek, 2008). This creates the illusion of unlimited choice when, in fact, this process restricts the number of choices that an individual will actually wish to make. The structure changes from the sovereign "thou shalt not", to the disciplinary "you should not want to", to the controlling "choose what you will (from the following list of options)". In sexual health practice, this transformation can be seen in the transition from abstinence-until-marriage as the only option, to the idea that only "abnormal" individuals do not comply with this dictum, and then, beyond this, to the harm reduction approach wherein a large list of sexual practices/lifestyle are acceptable. The legalization of many previously marginalized sexualities accomplishes two goals: first, it grants rights and freedoms to individuals who previously had to hide their sexualities, and second, it brings these individuals into the grasp of many surveillance mechanisms. Thus, the long list of acceptable sexualities exists with the proviso that individuals render themselves fully visible so that their practices can be known, tracked, and analyzed.

Another result is that many of the limitations are hidden underneath the possibility of selection. While individuals can select their preferred method of sexual contact, the list is never exhaustive. For example, while same-sex partnerships, anonymous sex, and barebacking, to name a few, may be sexual practices 
that are gaining acceptance within mainstream public health discourse, teen pregnancy is not. Indeed, one would be hard pressed to find any literature that presents the benefits of teen pregnancy. The new system is thus sufficiently flexible to allow a multitude of individualities, subjectivities, and differences to coexist, but only within pre-established boundaries - that is, freedom within limits (Deleuze, 1992).

Consequently, the individual may now feel compelled to express her or his uniqueness (see N. Rose on governing through freedom). In fact, he or she must reject the self-disciplinary goals of conforming to an expected norm, by instead conforming to the new norm of individuality. This signals the end of Foucault's (1977) disciplinary society - which makes each citizen into the specific type of person that he or she ought to be. Instead, we witness the effects of a control society, which functionally incorporates previous forms of resistance by accepting the politics of difference promoted by many postmodern thinkers as its new mantra. (See Empire by Hardt and Negri (2000) for a full discussion on the foregoing point.)

For example, individuals who prefer to work at home may now do so, provided that they are electronically connected to the workplace (e-mail, blackberry, etc.). While, at first glance, this seems to serve primarily as a concession to the employee's best interest, the interests of both employee and employer are met. He or she who works at home does not require dedicated on-site office space, including all of the amenities that correspond with this space, and which are paid for by the employer. Thus, an employee who works at home is an opportunity for the employer to both enhance employee satisfaction and to save money. The result is a capture of difference, a subjugation of pluralism, and an assimilation of postmodern values. The new mantra could be: "work as you wish, just ensure you work." The seemingly endless possibilities for employment efface the fact that working is the only viable option. Ultimately, and unfortunately, this means that by resisting, individuals are often doing little more than supporting that which they are attempting to oppose (Hardt and Negri, 2000). In summary, this means that in the society of control, the list of items deemed acceptable has expanded, but this has occurred with a corresponding increase in surveillance.

\section{The Public Health Surveillance Apparatus}

To exemplify this society of control, we will now provide an overview of the public health surveillance apparatus that is invoked in Ontario, Canada when an individual tests positive for a reportable sexually transmitted infection (STI) (which are, gonorrhea, chlamydia, and syphilis) or HIV/AIDS. To undertake this discussion, we will arbitrarily start at the point when an individual willingly undergoes STI/HIV testing and has his or her specimen sent to a laboratory. The selection of this period in the STI/HIV management sequence is that it is the point of the public health surveillance machine that many people, both in and outside of health care, know.

In addition, please note that while all of the infections discussed here may not be reportable in jurisdictions other than the one being discussed, for the intents and purposes of this paper, such specific regional differences are irrelevant for two main reasons. First, a review of Canadian, American, and European STI/HIV reporting guidelines revealed that infectious disease surveillance within these jurisdictions is sufficiently similar to allow for a generalized discussion; and, second, our goal is to reveal how the surveillance mechanisms that underpin the majority of North American and European public health apparatuses function as mechanisms of control, in the Deleuzian (1992) sense. Thus, we are not focusing on the effectiveness of regional STI/HIV practices, but rather, are identifying how current STI/HIV surveillance practices exemplify Deleuze's society of control.

To begin, in Ontario, Canada, if a reportable STI or HIV is detected in the blood, urine, or swab specimen that an individual submits as part of their sexual health examination, then the laboratory which performs the test must report this infection to both the site where the specimen was obtained (e.g., the office of the health care professional (HCP) who took the sample), and the local public health department. This dual reporting practice means that two simultaneous operations are initiated by one positive STI/HIV report: (1) the HCP who performed the STI/HIV test must begin the process of contacting and treating the 
STI/HIV-positive patient (henceforth referred to as the index case), and (2) an employee of the local public health department will create a file in which the epidemiological indicators (age, sex, geographical location, health insurance number, reported sexual practices, etc.) of the index case are permanently recorded. In Ontario, STI/HIV case managers input this information into the province-wide Integrated Public Health Information System (better known as iPHIS) (Association of Public Health Epidemiologists in Ontario, 2008). Access to this system is restricted, but for those with access, information can be obtained about anyone who has been entered across the entire province.

Furthermore, this reporting process is not optional; a provincial law, called the Health Protection and Promotion Act (HPPA), mandates its occurrence. This law supersedes all privacy laws, thus enabling the laboratory to transfer the index case's information to the health department without needing any form of consent. In addition, this law also stipulates that if an index case's official residence is in a jurisdiction other than the one wherein he or she was tested, then the notified public health department must transfer this information to the health department responsible for the region within which index case's home is located. If the index case resides in Ontario, iPHIS greatly facilitates this process. Inter-provincial communication, which is regrettably beyond the scope of this paper, is nevertheless slightly more complicated. All of this data collection, and possible transfer, occurs, however, unknown to the individual whose information is being processed. It also occurs without any requirement for consent. The outcome is that most people believe that STI/HIV management is quite straightforward: she/he visits an HCP, and provides a sample; the HCP then sends the sample to a laboratory; the lab tests the sample, and informs the HCP whether it is negative or positive; the HCP then informs the patient, and provides appropriate treatment.

As can be seen in the description above, the nature of the public health STI/HIV surveillance mechanism is both extensive and invasive. Even in the case of patient compliance to treatment, a network - both virtual and real - already consists of the index case, at least one HCP, laboratory technicians, and a vast computer database. This system also connects a minimum of three institutions - health clinic, laboratory, and one, or possibly two public health departments. In reality, however, the number of individuals involved in this specific example is higher than three. One must also include the endless number of researchers who developed the findings which guide the public health system, the array of civil servants who used this research to create the policies that structure this system, and the numerous legislators who transformed some of these policies into law.

Due to the interconnectedness of these varying groups, the public health department can be understood as one element of an otherwise invisible governmental check and balance system. One that functions by requiring duplicate (backup) reports from HCPs and from laboratories where positive diagnoses are made. While such a style of STI/HIV reporting occurs to reduce the likelihood that an index case might be overlooked, and thus that an individual could continue to unknowingly transmit his/her infection(s), this aspect of infectious disease surveillance reformulates public health as a political tool. Indeed, it positions public health reporting as a political machine which ensures that provincial legislation is followed properly. What is of particular importance is that this entire apparatus functions unknown to most individuals. They are processed, tracked, and analyzed, and then have their files indeterminately closed after appropriate action is taken, all without their ever knowing that such a process occurred. Provided that their information corresponds to all required verifications, they will remain ignorant of the data processing which occurred involving their information.

However, public health STI/HIV case managers do identify anomalies in the foregoing sequence. This, Deleuze would say, is the detection of an invalid password, the outcome being an interruption in the otherwise smoothly functioning and unnoticed surveillance machine. For example, during the case management process, the public health employee who is responsible for verifying proper STI/HIV management may find any of the following: an HCP may complete all requirements correctly, except for filing a report; an HCP may provide incorrect treatment; an HCP may not be able to locate and notify an index case; an index case may refuse, or fail to obtain, treatment; or an HCP may not notify an index 
case's sexual partners. In the first case, when an HCP has completed all duties correctly, except for filing a report, direct public health involvement is limited to gathering epidemiological information, and then creating a surveillance report from it. Most often, this process occurs without an index case having any knowledge that his or her information was transferred to the health department for tracking in the iPHIS system. The only additional step is that the local public health department contacts the HCP who collected the specimen from his/her patient.

In the second case, when an HCP provides incorrect treatment, the health department may ask an HCP to re-contact the index case in order to give the correct treatment. Alternatively, the health department may assume responsibility for the provision and direct supervision of treatment. If the former occurs, an index case will most likely remain unaware of the health department's involvement. However, if the health department does assume responsibility for treatment, an index case will be notified by letter, phone call, or personal visit from a public health worker. This is one of the first situations where the public health apparatus surfaces to the individuals that it tracks.

In the third scenario described above, a more extensive and elaborate set of procedures must be followed, all of which necessitate more direct and overt public health department involvement. For example, if an index case cannot be located, then the health department may check if there is a pre-existing iPHIS file containing identifiers which match those of the missing index case. If so, and if contact information is available, then the public health department may assume responsibility for contacting this individual. If such a match does not occur, then the new case will remain open indefinitely.

Similarly, if the index case fails to obtain treatment, public health officials in the majority of jurisdictions will usually contact the individual directly, and inform her or him of the need for treatment. This discussion may begin with a review of the negative health sequelae associated with non-treatment of the specific STI or HIV. However, in situations where, after notification, the index case still fails to obtain treatment, direct and overt legal mechanisms may be activated. These range from monetary fines to direct police involvement, including an indeterminate period of forced quarantine as mandated by the legislative authority of the Ontario Health Protection and Promotion Act (2005).

The last case to be addressed in this context (partner notification) constitutes a common form of public health involvement in STI/HIV management (Hogben, 2007). In most such cases, an HCP will have undertaken all relevant testing, treatment, and public health notification, but will subsequently request health department assistance in partner notification and follow-up. Research indicates that many HCPs welcome such assistance due to time, funding, and training limitations (Rogstad \& Henton, 2004; Tyden \& Ramstedt, 2000; Tomnay, Pitts, Fairley, 2004; Golden, Hopkins, Morris, Holmes, Handsfield, 2003). When this situation arises, the health department contacts an index case to request information about his or her previous sexual partners, and offer the individual the options of either personally contacting these partners, or having the health department do it for him/her without revealing the identity of the index case (see Cowan, French \& Johnson, 1996; Hogben, Brewer, \& Golden, 2007; or Golden, Faxelid, \& Low, 2008 for an in-depth discussion of partner notification).

In addition, public health departments are usually mandated to ensure that those who have been named as contacts undergo testing, and, if they test positive, to undergo treatment. To facilitate this process, health departments are often granted the legal authority to enforce testing on identified contacts (Sullivan et al., 2008). This means that if an individual is named as a contact by an index case, he or she loses the right to decline testing. Such legal power is granted in Ontario, Canada through the Health Protection and Promotion Act. However, because most persons who the health department knows had sexual contact with an identified STI/HIV case willingly (in fact, eagerly) undergo the testing process, these individuals never become aware that it is a legal necessity, with which they can be forced to comply (Cowan, French \& Johnson, 1996). Indeed, provided that all aspects of STI/HIV surveillance and control occur as dictated by law, most individuals remain ignorant to the fact that they ultimately have very few available options: by law, contacts must be tested, cases must be treated. 


\section{More on the Society of Control}

Up to this point, we have provided an overview of the intricate and intertwined public health surveillance system that regulates STI/HIV control. Now, we will illustrate how it exemplifies Deleuze's (1992) society of control: first, it deals with "dividuals", second, it is rhizomatic, and third, it functions based on passwords.

\section{STI/HIV Surveillance as "dividual-istic"}

In the 19th century, during the period that Foucault identified as disciplinary, STI public health strategies targeted "deviant" individuals who had become associated with STI transmission (McGough \& Handsfield, 2007). This resulted primarily in a strong public health focus on sex workers (McGough, 2008). Later, men who have sex with men became the prime targets of such initiatives. For example, in the mid-20th centuries, the US Park Service undertook what became known as the "Pervert Elimination Campaign" to stop men from having sex with each other in public parks (McGough \& Handsfield, 2007). In both this case and the one involving sex workers, the goal was to functionally eradicate a specific type of person: first, the prostitute, then the homosexual. Evidently, these goals were absolute failures. By today's standards, however, both of these STI control methods seem outright discriminatory. They fail to acknowledge the power differentials which result in higher infectious disease rates within certain populations, and they rely on the assumption that certain individuals are inherently deviant and in need of fundamental re-moulding. Ultimately, these strategies were disciplinary.

In contrast, the contemporary public health infectious disease surveillance apparatus, rather than isolating specific people as being in need of correction, deals with what Deleuze called "dividuals". In this new perspective, human bodies are seen as vectors of disease, infection, and illness, not as intrinsically deformed individuals who engage in proscribed sexual practices. This breaks the human body into an infinite number of pieces. It is no longer the terminal object of analysis. This, Haggerty and Ericson (2000) describe in relation to the surveillance assemblage, the system which separates bodies into discrete flows. As illustrated in the aforementioned description about STI/HIV surveillance in Ontario, Canada, present-day infectious disease strategies focus on locating and treating infections - not individuals. The infected body comes to be seen as little more than a transport medium, or the vector in the human-tohuman transmission chain (Waldby, 1996). This marks a significant change in public health management which can be best explained as aligning with society's transformation from a disciplinary society to one of control.

The outcome is that, now, it is of little to no concern that the people, who these infections colonize, are beings with personality and temperament. They have become objects, having lost their status as subjects. The bodies within which these infections reside come to be seen as STI transmission hubs. As Monahan and Wall (2007) suggest, "bodies are recast as nodes on vast information networks" (p.154). The individual is no longer the final, and indivisible, item of analysis in public health management. It is a thoroughly dividable object that can be penetrated and analyzed at greater and greater depths. Syndromes, not just identifiable pathogens, become acceptable foci for surveillance (French, 2009). Surveillance is no longer limited to gathering data about the outward shell of the body (Bogard, 2006); instead, in-depth testing methods, which surpass the surface of the skin, and public health surveillance techniques, which position the human body as a reservoir and transmission point for given infections, illustrate just how "dividual-istic", and thus controlling, current society has become. As Deleuze (1992) argued, the modern social system is one of pulsations, flows, and fluctuations - or, in other words, it is a rhizome.

\section{STI/HIV Surveillance as Rhizomatic}

At any given time, the entire public health STI/HIV surveillance apparatus may be simultaneously creating mass media campaigns about recent STI/HIV trends; sending nurses to provide sexual health education to individuals who will then deliver similar presentations to their peers; engaging in partner follow-up with individuals who have tested positive for a specific STI/HIV; contacting HCPs concerning 
patients who have tested positive for reportable STIs/HIV; having other individuals re-appraise their personal sexual practices in relation to mainstream ideologies of safer sex as a result of having been diagnosed with an STI/HIV; and making other individuals more responsive to mass media campaigns about other STIs/HIV due to positive diagnoses of a specific STI or HIV (Bloom \& Cohen, 2007; Vega \& Ghanem, 2007; Hogben \& Shrier, 2007).

As such, specimen collection is not the first step in STI/HIV management. Rather, it is an outcome of the cultural construction of what STIs/HIV are/is, and how people should respond to them/it. It is one step, among many, within a system of numerous connections and interrelationships. It is a collection of dividuals; that is: agencies, organizations, private citizens, and many others, all which can be considered dividuals, meld together to form a lateral conglomeration of seemingly independent, but actually interrelated, governmental institutions, non-governmental offices, public interest groups, volunteer groups, internet hosts, researchers, and individuals. Therefore, in contrast to the chronological description presented above, public health STI/HIV surveillance should not be envisioned as a linear model that starts with an individual self-selecting for STI/HIV testing.

Instead, we posit that the public health STI/HIV surveillance system is a pervasive network within which individuals are never at the beginning or at the end, but rather, are always in the middle. That is, the entire STI/HIV surveillance system is what Deleuze and Guattari (1987) called the rhizome. To explain the term, rhizome, we return to its original meaning, which was derived in the 19th century from the Greek word rhizôma to describe a root-like subterranean stem that usually produces roots from its lower surface, and sends up stems progressively from its from upper surface (The Random House Dictionary, 1987). Deleuze and Guattari (1987) modified this definition to encompass a concept of social structures, which could be better defined as a matrix. Any point can be connected, unconnected, and reconnected to any other point (Deleuze \& Guattari, 1987). Consequently, no matter where one is (whether as patient, HCP, or public health worker, for example), one is always caught in the public health surveillance apparatus. This place, Deleuze and Guattari (1987) posit, resembles an intermezzo - a small section in a musical or theatrical performance that is always between items, but is not part of either. Thus, the rhizome is a field of impulses and intensities that have no distinct boundaries. It is a domain of pure energy, despite the fact that society often imposes structure and order onto it.

Understanding the public health surveillance system as rhizomatic helps reposition it as a multi-directional network of power(s) that interrelates in all possible directions. Each individual, not just public health professionals, now ensures that friends, family, and acquaintances all remain within the boundaries of the social norms. We are all observers of one another (Mathiesen, 1997). This produces a system which goes well beyond the mechanism that Foucault (1977) described as the panopticon. Indeed, the panopticon, in its true form, is based on invisible observation from a visible source (Foucault, 1977). Deleuze's work supports that of Lyon (2006), and suggests that perhaps it is time to move beyond the panopticon as the primary concept for understanding surveillance. This leads to the assertion that in modern society, observation is pervasive: panoptic, seen, and unseen. Ultimately, it is ubiquitous. Each of us looks both outward and inward to enforce docility, obedience, and normative behaviour in ourselves and others; and a pervasive network watches and evaluates our every movement. The former techniques are disciplinary, the latter controlling. The surveillance institution no longer resides within one given building, being enforced and regulated by one specific set of individuals. Rather, it is pervasive, accumulating its data unknown to most, exacting its effects across the entire network.

In Ontario, Canada, we can see the society of control demonstrated quite clearly by the aforementioned public health STI/HIV mechanisms. In this example, observation occurs from everywhere: patients, clinicians, laboratories, health departments, and so forth. The outcome is that while a system exists which can force STI/HIV testing, it rarely needs to do so. Personal and social perceptions about STIs and HIV ensure that the STI/HIV testing of known cases and contacts typically takes place without active enforcement by public health authorities (Cowan, French \& Johnson, 1996). Individuals undergo routine $\mathrm{STI} / \mathrm{HIV}$ screening and treatment as a social responsibility, to demonstrate their citizenship, not as a 
violation of their personal rights (O'Byrne \& Holmes, 2007). Submitting one's body to both external and internal examination is a duty, not an unacceptable corporeal invasion. Thus, the individual (or the dividual more precisely) who does not possess the self-motivation to police his or her own behaviour is perpetually in conflict with a variety of external sources (friends, family, government, peers, etc.) who all function in unison to correct non-normative practices. When these disciplinary techniques fail, however, control mechanisms ensure appropriate cooperation. At every given moment, an interconnected array of tracking devices captures our every action and permits us to continue doing what we were doing provided that our passwords are valid.

\section{STI/HIV Surveillance as a Password System}

In their book, Empire, Hardt and Negri (2000) argue that this web-like increase in connections between different agencies and groups has transformed the rhizome from a striated medium (the ridges between the connections) into a smooth one because the connections have become so densely packed that the ridges between them have been eliminated. For these authors (2000), the connections have become so ubiquitous that the individual cannot escape, cannot resist, cannot revolt. See for example, the 2006 BBC report on the high level of surveillance in Britain. We believe, however, that while the current system may appear to be smooth, it remains stratified. The main difference is that the striation is now so extensive that it appears to be smooth. In other words, the linkages have become so numerous that the striations have woven a social fabric that is pliable, but pervasive, present, but unnoticeable. Like air, it is everywhere, but invisible to the naked eye. Deleuze's (1992) work on the society of control is thus the 'microscope' which permits an more in-depth analysis to reveal another component and aspect of the current public health surveillance apparatus: its password-based structure.

It is at this precise point when one acknowledges that infectious disease surveillance is a pervasive social machine that one can begin to recognize what Deleuze (1992) called the society of control: regardless of whether or not an individual has the potential to question social norms, the society of control has become so saturated with connections that the individual is continuously being monitored and subtly directed by the contemporary notions of appropriate behaviour. Perpetual surveillance within the society control allows for the capture and analysis of an individual's every movement, and ever-occurring modifications are made based on this information. These modifications involve decisions about whether or not a given individual should be granted access to the information that they request. The question becomes: does the submitted password warrant admission? The society of control thus imposes physical barriers ex post facto - after the submitted password has been deemed unacceptable, restriction is imposed. At this point, punitive outcomes may occur.

Public health STI/HIV management can be considered one activity in which access is granted or denied. While this limitation can take the form of forced quarantine, the frequency of this public health practice has diminished in recent years. In STI/HIV management and control, this mostly occurred due to severe public backlash to public health's discriminatory practices of segregating identifiable populations (Ontario Advisory Committee on HIV and AIDS, 2002). For example, in Ottawa, Ontario, this law was used excessively in relation to gay and bisexual men, and has produced lasting tensions between this community group and the public health department.

The outcome of physical quarantine being used less frequently is that public health departments appear to have adopted a laissez-faire approach which permits all sexual and behavioural practices to occur. This is greatly facilitated by the dividualistic approach to infectious disease management, which replaced the preceding focus on deviant sexual sub-cultures. Public health employees, for example, do not publically denounce anal sex between men as deviant or abnormal anymore. This, Lianos (2003) called control "that is not oriented toward values" (p.412). Thus, instead, public health authorities meticulously track infections which can be transmitted by unprotected sex, and impose sanctions on individuals who carry given bacteria and viruses. Greater sanctions are imposed on those who have unprotected sex and also have an STI or HIV. This, Deleuze (1992) would argue, is the process by which individuals navigate the 
current sexual landscape by means of passwords. If a sexually transmitted organism infects one's body, then one cannot have unlimited access to the sexual domain. One's password becomes limited.

In practice, this amounts to public health departments notifying index cases and their sexual partners, and imposing limitations on these individuals as need be. This resembles the methods by which credit card companies freeze accounts when they suspect fraud. Open access is permitted until the surveillance mechanism identifies an abnormality, whether this is the presence of an infectious disease or fraudulent credit card activity. Much like the credit card company, such password restriction often occurs after unwanted dealings (e.g., after STI/HIV transmission) have occurred. Nevertheless, within the society of control, the goal is still to enhance surveillance in an effort to improve real-time password limitation. Restricting behaviour, as would have occurred in the disciplinary society is much less important.

As an example of the foregoing, the password-impositions which public health departments place on individuals, in addition to the requirement to seek treatment, is that for treatable STIs, such as gonorrhea and chlamydia, a seven-day period of abstinence is also ordered (Public Health Agency of Canada, 2006). This period ensures complete treatment, and thus eliminates the possibility of further STI transmission. Failure to observe this period may result in further sanctions: the individual will require re-treatment to ensure adequate eradication of the infection. If compliance is not obtained, legal mechanisms can be initiated, such as monetary fines and forced administration of treatment (Health Protection and Promotion Act, 2005). In relation to HIV, however, the heath department must inform patients that their sexuality is forever changed. People who live with HIV/AIDS must disclose their HIV sero-status prior to all sexual encounters in which HIV could be transmitted (Canadian AIDS Society, 2004). Their sexual passwords have been irreparably modified, thus changing what they will have access to.

\section{Final Remarks}

In this paper, we used the current public health STI/HIV surveillance mechanism that is activated when an individual tests positive for a reportable STI/HIV to substantiate Deleuze's (1992) thesis that contemporary society has become one of control. To accomplish this, we argued that testing positive for an STI/HIV is actually a much more involved process than many individuals may believe; that is, we described how public health involvement in STI/HIV control extends far beyond (1) the mere collection and testing of specimens, and (2) the as needed dispensing of appropriate treatment. As part of this, we showed that the entire public health surveillance apparatus that deals with STIs/HIV produces much more inclusive (and invasive) effects than could be achieved by one simple agency. Next, we delineated the interconnected nature of many different agencies, all of which co-function to ensure that specific outcomes occur regardless of how resistant an individual may attempt to be. This was the carefully executed STI/HIV reporting machine, which involves the precise cooperation of health care professionals, public health laboratories, public health departments, patients, and policy workers, to name a few. The outcome of this discussion was the finding that public health practice is "dividual-istic", rhizomatic, and based on passwords. Stated succinctly, this means that the modern public health STI/HIV system exemplifies Deleuze's concept of the society of control because it is highly pervasive, increasingly intertwined (i.e., rhizomatic), and ultimately controlling.

\section{Acknowledgement}

The authors would like to thank the Canadian Institutes of Health Research (CIHR), the Institute of Gender \& Health, and the Institute of Infection and Immunity, for their support. 


\section{References}

Arendt, H. 1968. The Origins of Totalitarianism. New York: Harcourt.

Association of Public Health Epidemiologists in Ontario. Integrated Public Health Information System (iPHIS). http://www.apheo.ca/index.php?pid=187. October $23^{\text {rd }} 2009$.

BBC. 2006. Britain is “surveillance society”. http://news.bbc.co.uk/2/hi/uk news/6108496.stm. 3rd November 2008.

Bloom, F.R, and D.A. Cohen. 2007. Structural interventions. In S.O. Aral. J.M. Douglas Jr. (eds.) and J.A. Lipshutz (assoc ed.) Behavioral Interventions for Prevention and Control of Sexually Transmitted Diseases. New York: Springer Science+Business Media,125-141.

Bogard, W. 2006. Surveillance assemblages and lines of flight. In D. Lyon (ed.) Theorizing Surveillance: The Panopticon and Beyond. Devon, UK: Willan Publishing, 97-122.

Canadian AIDS Society. 2004. Disclosure of HIV Status after Currier: Resources for Community-Based AIDS Organizations. Ottawa, Ontario: Health Canada.

Cowan, F.M., R. French and A.M. Johnson, 1996. The role and effectiveness of partner notification in STD control: a review'. Genitourinary Medicine 72: 2467-252.

Deleuze, G. 1992. Postscript on the Societies of Control. October 59: 3-7.

Deleuze, G. 1998. Having an idea in cinéma (on the cinéma of Straub-Huillet). In E. Kaufman and K.J. Heller (eds.) Deleuze and Guattari: New Mappings in Politics, Philosophy, and Culture. Minneapolis: Minnesota University Press, 14-19.

Deleuze, G and F. Guattari. 1987. A Thousand Plateaus: Capitalism and Schizophrenia. Minneapolis: Minnesota University Press.

Deleuze, G and F. Guattari, F. 1983. Anti-Oedipus: Capitalism and Schizophrenia. Minneapolis: Minnesota University Press.

Donzelot, J. 2005. La police des familles. Paris: Édition Reprise.

Foucault, M. 1997. The Politics of Truth. Los Angeles: Semiotext(e)

Foucault, M. 1991. Governmentality. In G. Burchell, C. Gordon and P. Miller (eds.) The Foucault Effect. Chicago : The University of Chicago Press, 197-210.

Foucault, M. 1986. The Care of the Self: The History of Sexuality, Volume Three. New York: Vintage.

Foucault, M. 1985. The Use of Pleasure: The History of Sexuality, Volume Two. New York: Vintage.

Foucault, M. 1978. The History of Sexuality: An Introduction, Volume One. New York: Vintage.

Foucault, M. 1977. Discipline and Punish. New York: Vintage.

French, M.A. 2009. Woven of war-time fabrics: the globalization of public health surveillance. Surveillance \& Society 6(2), 101115.

Golden, M.R., S.G. Hopkins, M. Morris, K.K. Holmes, and H.H. Handsfield. 2003. Support among persons infected with HIV for routine health department contact for partner notification. Journal of Acquired Immune Deficiency Syndromes 32: 196202.

Golden M.R. E. Faxelid, and N. Low. 2008. Partner notification for sexually transmitted infections including HIV infection: an evidence-based assessment. In K.K. Holmes, P.F. Sparling, W.E. Stamm, P. Piot, J.N. Wasserheit, L. Corey, M.S. Cohen and D.H. Watts (eds). Sexually Transmitted Diseases, $4^{\text {th }}$ Edition. New York: McGraw Hill, 965-984.

Haggerty, K.D. and R.V. Ericson. 2000. The surveillant assemblage. British Journal of Sociology 51(4): 605-622.

Hardt, M and A. Negri. 2000. Empire. Massachusetts: Harvard University Press.

Hogben, M. 2007. Partner notification for sexually transmitted diseases. Clinical Infectious Disease, 44(Suppl 3): S160-S174.

Hogben, M., and L.A. Shrier. 2007. Interventions in sexual health care-seeking and provision at multiple levels of the U.S. health care system. In S.O. Aral. J.M. Douglas Jr. (eds.) and J.A. Lipshutz (assoc ed.) Behavioral Interventions for Prevention and Control of Sexually Transmitted Diseases. New York: Springer Science+Business Media, 190-213.

Hogben, M, D.D. Brewer, D.D. and M.R. Golden. 2007. Partner notification and management interventions. In S.O. Aral. J.M. Douglas Jr. (eds.) and J.A. Lipshutz (assoc ed.) Behavioral Interventions for Prevention and Control of Sexually Transmitted Diseases. New York: Springer Science+Business Media, 170-189.

Holland, E. 1998. From schizophrenia to social control. In E. Kaufman and K.J. Heller (eds.) Deleuze and Guattari: New Mappings in Politics, Philosophy, and Culture. Minneapolis: Minnesota University Press, 65-73.

Lianos, M. 2003. Social control after Foucualt. Surveillance \& Society 1(3): 412-430.

Lupton, D. 1995. The Imperative of Health: public health and the regulated body. London: Sage.

Lyon, D. 2006. The search for surveillance theories. In D. Lyon (ed.) Theorizing Surveillance: The Panopticon and Beyond. Devon, UK: Willam Publishing, 3-20.

Mathiesen, T. 1997. The viewer society: Michel Foucault's 'panopticon' revisted. Theoretical Criminology 1(2): $215-233$.

McGough, L.J., and H.H. Handsfield. 2007. History of behavioural interventions in STD control. In S.O. Aral. J.M. Douglas Jr. (eds.) and J.A. Lipshutz (assoc ed.) Behavioral Interventions for Prevention and Control of Sexually Transmitted Diseases. New York: Springer Science+Business Media, 3-22.

McGough, L.J. 2008. Historical perspectives on sexually transmitted diseases: challenge for prevention and control. In K.K. Holmes, P.F. Sparling, W.E. Stamm, P. Piot, J.N. Wasserheit, L. Corey, M.S. Cohen and D.H. Watts (eds). Sexually Transmitted Diseases, $4^{\text {th }}$ Edition. New York: McGraw Hill, 3-11.

Monahan, T. and T. Wall. 2007. Somatic surveillance: corporeal control through information networks. Surveillance \& Society 4(3): 154-173.

O'Byrne, P. and D. Holmes. 2008. Evaluating crack pipe distribution in Canada: A systems change case study. Addiction Research and Theory 16(2): 181-192.

O’Byrne, P. and D. Holmes, D. 2007. The micro-fascism of Plato's good citizen: producing (dis)order through the construction of 
risk. Nursing Philosophy 8: 92-101.

Ontario Advisory Committee on HIV and AIDS. 2002. Reducing HIV Transmission by People With HIV Who Are Unwilling or Unable to Take Appropriate Precautions.

http://www.google.ca/\#hl=en\&safe=off\&q=section $+22+$ orders + ontario + HIV \&meta= \&fp=3029a5b53e382201 $23^{\text {rd }}$ October 2009

Ontario Government. 2005. Health Protection and Promotion Act. http://www.elaws.gov.on.ca/html/source/regs/english/2005/elaws src regs r05001 e.htm. 29th September 2008.

Paxton, R.O. 2004. The Anatomy of Fascism. New York: Penguin.

Paxton, R.O. 1998. The five stages of fascism. Journal of Modern History 70: 2-22.

Public Health Agency of Canada. 2006. Canadian Guidelines on Sexually Transmitted Infections, 2006 Edition. Ottawa: Queen's Printer.

Rainbow, P. 1984. The Foucault Reader. Toronto: Pantheon.

Remis, R., C. Swantee, L. Schiedel, and J. Liu. 2007. Report on HIV/AIDS in Ontario. http://www.phs.utoronto.ca/ohemu/tech\%20reports.html. $1^{\text {st }}$ November 2008.

Rogstad, K.E. and L. Henton. 2004. General practitioners and the national strategy on sexual health and HIV. International Journal of STD \& AIDS, 15: 169-172.

Rose, N. 1999. Powers of Freedom. Cambridge: Cambridge University Press.

Sullivan P.S., W.C. Levine, M.T. McKenna, and H. Weinstock. 2008. Innovations in public health surveillance for HIV/AIDS and other STDs: guideposts for prevention and care. In K.K. Holmes, P.F. Sparling, W.E. Stamm, P. Piot, J.N. Wasserheit, L. Corey, M.S. Cohen and D.H. Watts (eds). Sexually Transmitted Diseases, $4^{\text {th }}$ Edition. New York: McGraw Hill, 1867-1893.

The Random House Dictionary of the English Language, Second Edition, Unabridged. 1987.

Tomnay, J.E., K. Pitts, C.K. Fairley. 2004. Partner notification: preferences of Melbourne clients and the estimated proportion of sexual partners they can contact. International Journal of STD \& AIDS 15: 415-418.

Tyden, T. and K. Ramstedt. 2000. A survey of patients with Chlamydia trachomatis infection: sexual behaviour and perceptions about contact tracing. International Journal of STD \& AIDS 11: 92-95.

Vega, M.Y. and K.G. Ghanem. 2007. STD prevention communication: using social marketing techniques with an eye on behavioural change. In S.O. Aral. J.M. Douglas Jr. (eds.) and J.A. Lipshutz (assoc ed.) Behavioral Interventions for Prevention and Control of Sexually Transmitted Diseases. New York: Springer Science+Business Media, 142-169.

Waldby, C. 1996. AIDS and the Body Politic: Biomedicine and Sexual Difference. London: Routledge.

Zizek, S. 2008 Violence. New York: Picador Paperback. 